\title{
Temporal Development of Scour Holes around Submerged Stream Deflectors
}

\author{
Karen Rodrigue-Gervais ${ }^{1}$, Pascale M. Biron ${ }^{2} *$ and Michel F. Lapointe ${ }^{1}$ \\ ${ }^{1}$ Department of Geography, McGill University, 805 Sherbrooke St. W., Montreal, QC, Canada, \\ H3A 2K6; karen.rodrigue-gervais@mail.mcgill.ca; michel.lapointe@mcgill.ca \\ ${ }^{2}$ Department of Geography, Planning, and Environment, Concordia University, 1455 De \\ Maisonneuve W., Montreal, QC, Canada, H3G 1M8; pascale.biron@concordia.ca \\ *Corresponding author
}




\begin{abstract}
Although the deflector structures used in many fish habitat rehabilitation schemes are frequently overtopped, few studies have examined the scour patterns created around submerged models. Furthermore, laboratory studies typically test smooth-surfaced structures, when those installed in natural rivers are generally made of logs or boulders. This study uses rough-surfaced, paired deflectors to investigate the temporal evolution of scour for three overtopping ratios in identical approach flow conditions in a flume. Results show that when maintaining identical discharge, raising deflector height and thus reducing the overtopping ratio (flow depth / structure height), an increased depth and volume of scour is generated next to the structures. The location of maximum depth and the rate of scouring with time is similar for the two highest deflectors (overtopping ratios of 1.22 and 1.83), but different for the lowest deflector model (overtopping ratio of 3.67). In order to improve the success rate of river restoration projects using in-stream structures, the overtopping ratio should be used in equations that predict scour depth evolution with time.
\end{abstract}

Key words: spur dykes, groynes, abutment, overtopping, river restoration, fish habitat, pool 


\section{Introduction}

Flow deflectors used in fish habitat restoration schemes are designed to be frequently overtopped (Kuhnle et al. 2002). Though some studies have examined the complex threedimensional flow field that occurs around submerged deflector-like structures (Tominaga et al. 2000; Biron et al. 2005; Uijttewaal 2005; McCoy et al. 2007; Kunhle et al. 2008), only few have investigated the scour patterns generated under these flow conditions (Kunhle et al. 1999; 2002; Thompson 2002a; Biron et al. 2004a). The overtopping ratio (total depth of flow $z$ divided by the height of the structure $h$ ) exhibits a complicated relationship with scour volume and depth, for different approach flow intensities - a parameter defined by Melville (1992) (Kuhnle et al. 2002). A better understanding of the impact that the height of these structures has on scouring is important since the prevailing standard is to design deflectors as low-water devices submerged well below the water surface during higher flows, to preclude their demolition by currents or floating debris (Swales 1989; Rundquist and Baldrige 1990; Hey 1994; Thompson 2002a). While a design that is too high may lead to unnecessarily high flow resistance during flood conditions, structures that are too low decrease their capacity to confine the flow during average discharges, and risk producing pools insufficiently deep or voluminous for fish (Uijttewaal 2005; McCoy et al. 2007).

Most - if not all - previous studies have used smooth-surfaced structures in laboratory experiments, while in rivers deflectors tend to be made of logs or boulders. Furthermore, the role of in-stream structure height on the temporal evolution of the scour hole has not been well documented: most of the studies conducted on deflectors or analogous structures (e.g. bridge abutments) have only examined equilibrium values of scour (Melville 1995; 1997; Kunhle et al. 2002; Biron et al. 2005; Dey et al. 2008).

In order to help understand the scouring process during overtopping conditions, we investigate in a laboratory flume the temporal and spatial evolution of scour for three different submerged deflector heights in identical approach flow conditions. In all experiments, the deflectors include a surface roughness component.

\section{Methodology}

Laboratory experiments were conducted in a $4 \mathrm{~m}$ long, $0.6 \mathrm{~m}$ wide rectangular flume in the Civil Engineering Hydraulics Laboratory at McGill University (Canada). Plexiglass walls were 
inserted into the flume, reducing its width to $0.4 \mathrm{~m}$. A floating Styrofoam pad was also placed atop the water surface in the inlet zone to inhibit flow concentrations, dissipate excess energy and minimize wavy surface patterns.

A sediment recess $0.375 \mathrm{~m}$ deep, $0.4 \mathrm{~m}$ wide and $1.52 \mathrm{~m}$ long was installed $1.6 \mathrm{~m}$ downstream from the flume inlet. This basin was filled with uniform-sized sand with a geometric standard deviation $\left[\sigma_{g}=\left(d_{84} / d_{16}\right)^{1 / 2}\right]$ of 1.07 . The sand was sorted to pass through a $1.19 \mathrm{~mm}$ sieve but not through a $1 \mathrm{~mm}$ mesh (median particle diameter $d_{50}=1.10 \mathrm{~mm}$ ) so no ripples on the bed formed (Melville 1997). For the remaining flume length (upstream and downstream from the basin), a false floor was elevated above the flume bed, level with the sand in the sediment recess. The same-sized sand grains were glued permanently to this fixed flat surface, following the practice described in Kwan and Melville (1994), Ahmed and Rajaratnam (1998) and Dey and Barbhuiya (2006).

The impact of deflector height on scouring was tested using a pair of deflectors oriented perpendicular $\left(90^{\circ}\right)$ to the channel walls and submerged below the water surface (H90 series hereafter). The deflector skeletons were built from Plexiglass and then covered in uniform gravel $\left(d_{50}=1.59 \mathrm{~mm}\right)$, with marine epoxy, to create a component of roughness. Deflectors (including roughness) were $3 \mathrm{~cm}$ wide and $10 \mathrm{~cm}$ long, corresponding to a contraction ratio (length of both deflectors/channel width) of 0.50 . Three heights $h$ were used, extending $9 \mathrm{~cm}, 6 \mathrm{~cm}$, or $3 \mathrm{~cm}$ above the initial pre-deformation bed and leading to overtopping ratios $(z / h)$ of $1.22,1.83$ and 3.67 , respectively. In all cases, the upstream discharge $\left(0.013 \mathrm{~m}^{3} / \mathrm{s}\right)$, slope $(0.0007)$ and depth $(0.11 \mathrm{~m})$ remained the same. The Reynolds number was 28721 and the Froude number, 0.29. The ratio of bed shear to critical shear velocity $\left(u *_{u} *_{c}\right)$ for the approach flow was set at 0.97 , a value selected to be close to 1 to obtain the greatest possible depth of scour near the deflectors, where stresses are intensified (Melville and Chiew 1999; Ettema et al. 2000). Shear velocity was obtained from the logarithmic profile method (Biron et al. 2004b). Velocity was measured with an Acoustic Doppler Velocimeter (ADV) in a $1 \mathrm{~cm}^{3}$ sampling volume located $5 \mathrm{~cm}$ below the probe at a frequency of $25 \mathrm{~Hz}$ for 1 minute. ADV data were filtered using the phase-space despiking algorithm developed by Goring and Nikora (2002) and later modified by Wahl (2003). Eight or more vertical positions were sampled in the center of the channel upstream from the deflectors, with at least 5 of these points located within the bottom $20 \%$ of the flow (Biron et al. 1998). The 
critical shear velocity $(0.029 \mathrm{~m} / \mathrm{s})$ was determined from an updated version of Shields curve (Yalin and Karahan 1979) based on $d_{50}$.

A Vernier point-gauge was mounted on a sliding metal carriage to measure bed surface elevations. The precision of this instrument in the vertical dimension is $0.1 \mathrm{~mm}$, and $1 \mathrm{~mm}$ in the longitudinal $(x)$ and lateral $(y)$ directions. For each experiment, a scraping blade was attached to the sliding metal carriage, to level the bed in the recess basin. Subsequently, the flume pump was started gradually and set to the desired discharge within a period of fifteen seconds. Maximum scour depth measurements and full bed topography surveys were then conducted at select time intervals, with these time intervals becoming more spaced in time throughout the course of the runs (depth: 5, 10, 15, 20, 25, 30, 45, 60, 90, 120, 180, 240, 300, 360, 420, 480, 540, 600, 720, $840,960,1080,1200,1500,1800,2400$, and 3000 minutes; full bed: 5, 30, 120, 600, 1200, 1800 and 3000 minutes). For each topography measurement sequence, the pump was stopped gradually within fifteen seconds but the water was not drained. Maximum scour depths were uncovered by sampling at least four topography readings in the scour hole surrounding each of the deflectors. For the full bed surveys, measurements were performed according to a $2 \times 2 \mathrm{~cm}$ grid in the zone of intense scouring with a decreased resolution further away (approaching the flat bed). All the topography data were processed within a Geographic Information System software (ArcGIS, version 9). Digital Elevation Models (DEM) were created by interpolation and were then used to estimate the volume and longitudinal length of scour. The latter parameter was defined as the sum of the maximum upstream length and maximum downstream length of the scour hole relative to the deflector. The scour depth, volume and length results presented in the following section are an average of the values recorded next to each of the paired deflectors.

Although the experiments were conducted for a lengthy period of time (50 hours), the size of the pools was still evolving at the end of each run. Melville and Chiew (1999) and Oliveto and Hager (2002) have noted that it may take as many as several days for equilibrium conditions to be attained in small-scale laboratory experiments. Scour depth values at the end of the runs $\left(d_{s e}\right)$ were used as a proxy for equilibrium conditions and equilibrium time $\left(t_{e}\right)$ was set equal to 3000 $\min$. 


\section{Results}

\section{Scour development}

Bed topography at various stages of pool development for each of the three runs is shown in Figure 1. Scouring in all cases began at the deflector tips and resulted in deposition downstream. However, both the rate of scouring and the ensuing pool morphology differed greatly between experiments. In the run where the structures were highest (H90-1, Figure 1a), the scour holes next to each deflector had already merged in the center of the channel after 5 minutes, whereas for the medium height deflectors (H90-2, Figure 1b), distinct pools at the tip of each deflector and distinct little mounds of deposition just downstream had just formed. More surprising though was the case of the lowest deflector model (H90-3, Figure 1c), for which no scouring could visually be reported after 5 minutes. Over time, the deflector pools elongated and grew in depth and width as they approached equilibrium. For the medium height deflectors (Figure 1b), the scour holes eventually came to extend laterally to both the upstream and downstream channel walls, and to merge in the middle of the channel, similarly to the pattern created by the highest deflectors (Figure 1a). In contrast, the pools produced by the lowest deflectors remained separate and never expanded to the downstream walls, preserving instead a kidney-like shape throughout the duration of the run (Figure 1c).

\section{Scour depth}

Figure 2 illustrates the asymptotical trend in the temporal evolution of scour depth $\left(d_{s}\right)$ for all runs, with the highest rates of scour being produced initially and then continually decreasing. The depth of scour at the end of the observed period was still increasing (Figure 2a), indicating that an equilibrium condition had not yet been reached. After 3000 minutes run time, the highest deflectors (H90-1) had produced depths 1.40 times greater than the medium height deflectors, and 2.32 times deeper than the low ones (Figure 2a). Throughout the run duration, the highest deflector model always produced the greatest values, and the lowest model, the smallest. However, when relative scour depth is plotted against normalized time, the curves for the high and medium deflectors collapse, but that of the lowest deflectors (H90-3) remains distinct (Figure 2b). Hence, the high and medium deflectors behave the same way, with $80 \%$ of the final scour depth observed occurring in only $14 \%$ of the total run time. Conversely, $40 \%$ of the run duration was necessary for the lowest deflectors to yield $80 \%$ of their final scour depth. 
In addition to differences in the progress rate of scour depth between high/medium deflectors and low deflectors, the position of the maximum scour depth around the structures also varied between models. Both the high and medium height deflectors produced maximum depths at the tip of the structures, whereas the lowest deflectors typically produced them along the upstream face. These differences in depth location cannot be explained as resulting from differences in the irregular surface of the different rock-covered models, since Kuhnle et al. (1999) also observed the same pattern (with increased overtopping) around a smooth side-sloped deflector.

Best-fit equations for the temporal development of scour depth normalized by final run values are presented in Table 1. The type of function used (e.g. logarithmic, power, or higher order polynomial) to describe each run was selected according to the following criteria: that it 1) respect a normal and random distribution of the residuals about the line; 2) produce the highest coefficient of determination $\left(R^{2}\right)$; and 3) be as simple as possible (anything higher than a third order polynomial can be difficult to explain in nature). The best-fit equations for the highest and medium height deflectors (H90-1 and H90-2) are power law functions, with very similar coefficients and scaling exponents. Hence, a single best-fit equation can be used to explain both data sets:

$$
d_{s} / d_{e}=1.003\left(t / t_{e}\right)^{0.12}
$$

This relationship is strong, with $R^{2}=0.975$. The relative scour depths around the lowest deflectors (H90-3) were better explained by a logarithmic curve than by a power function, with an $R^{2}$ value of 0.987 (Table 2). However, the required condition for this type of regression of randomly distributed residuals was not respected.

\section{Scour length and volume}

The maximum length of pools $\left(l_{s}\right)$ as well as their volume $\left(v l_{s}\right)$ exhibited the same trends with time as scour depth, though a little less clearly, as the values were calculated based on interpolation of topographic data. At the end of the runs, the scour length for the high deflectors (H90-1) was respectively 1.82 and 3.65 times that of the medium and lowest deflectors (Table 2). It should be noted that the topography measurement cross-sections for the H90-1 run were spread further apart, so that, comparatively, an overestimation of scour length may have occurred.

With respect to volumes, the high deflectors (H90-1) produced 2.11 times more than the medium height deflectors and, remarkably, 12.86 times more than the lowest (Table 2). Note that 
a greater error would be expected in volume than in scour length, given that volume results from interpolation in three dimensions.

\section{Relationships between scour dimensions}

An ordinary least-squares regression was used to assess the temporal relationship between $d_{s}$ and $l_{s}$ for all runs. However, the values from the H90-1 run were omitted from the regression analysis since scour lengths in this experiment were likely overestimated during interpolation. Inclusion of these data points still lead to a high coefficient of determination between variables $\left(R^{2}=0.95\right)$, but skewed the slope and intercept values of the equation. The regression equation (with $d_{s}$ and $l_{s}$ in $\mathrm{cm}$ ) was:

$$
d_{s}=0.19\left(l_{s}\right)+0.48
$$

The coefficient of determination obtained for this relationship was 0.98 .

Regression analysis was also used to determine whether a strong predictive relationship exists between scour depth and volume. Best characterized by a power function, this relationship had a coefficient of determination of 0.99 :

$$
\operatorname{vol}_{s}=3.87\left(d_{s}\right)^{3.0}
$$

Kuhnle et al. (2002) as well as Biron et al. (2004a) developed similar predictive equations for equilibrium scour volume. However, the value for the constant proposed by Kuhnle et al. (2002) was 12.11 and by Biron et al. (2004a), 1.6, indicating a considerable variability. Note that our data show that the relationship between depth and volume (Equation 3) is consistent throughout the temporal development of the scour hole. Relating volume to the scour length using both Equations 2 and 3 reveals that the width of the scour hole corresponds to approximately $75 \%$ of the scour depth. Meanwhile, pool length, throughout the runs, was five times greater than depth (Equation 2).

\section{Discussion}

Our results reveal that an increase in deflector height results in a greater depth, length, and volume of scour. Likewise, structure overtopping (the ratio of water depth to structure height) affects the potential of deflectors to create a large pool: a larger overtopping ratio reduces scouring. In contrast with our results, however, Kuhnle et al. $(1999 ; 2002)$ present evidence that increasing the overtopping ratio of a submerged deflector can lead to a greater pool volume. This 
discrepancy may be due to the fact that in Kuhnle's tests, flow depth was the parameter varied to alter the overtopping ratio, while in ours, it was deflector height. As Kuhnle et al. $(1999 ; 2002)$ increased flow depth, an increase in the mean and surface upstream flow velocities was also needed to conserve the same shear velocity (and state of particle mobility) on the upstream bed. This may have enlarged the stagnation-pressure heads and created a steeper adverse pressure gradient at the deflector face, potentially forcing greater pool depths and volumes (Ettema et al. 1998). By opposition, such flow considerations are not an issue in our study, as identical conditions were maintained between runs. Hence, our data clearly demonstrate that reduction in the overtopping ratio increases the depth and volume of scour next to a submerged deflector.

Another key contribution of our study is that it highlights a dissemblance in the scouring behaviour that occurs next to short versus medium-to-high structures. Indeed, self-similarity was seen to exist for the process of scour depth as well as length for the high and medium models, but not for the lowest structures (Figures 2b). Moreover, the greatest scour depths, over time, almost always took place at the upstream face of the structure for the lowest paired deflectors, yet dissimilarly, at the tip of the deflector for the medium and highest cases. Evidently, flow patterns are affected by the structure overtopping ratio. Unfortunately, previous studies which have examined the detailed flow field around submerged deflector-like structures have not tested this effect as they focused only on one overtopping ratio (Biron et al. 2005: $z / h=1.27$; McCoy et al. 2007: $z / h=1.4$; Kuhnle et al. 2008: $z / h=2.0$ ). Note that Uijttewaal (2005) did investigate two overtopping ratios $(z / h=1.2$ and 1.4$)$ but he did not include a detailed comparison of the impact of the overtopping ratio on the flow field.

In our flume experiments, adjustments in pool length over time related strongly to changes in pool depth: a unit increase in depth matched a fivefold increase in length. However, Thompson (2002b) estimated, based on laboratory data, that the coefficient in the linear relationship between pool length and depth at equilibrium is closer to a factor of 10 . The difference in value may be explained in part by the fact that Thompson's experiments specifically looked at the impact of changing channel gradient on pool morphology - a parameter not varied here. In his experiments, pools were found to elongate in response to increases in bed slope, in order to minimize the rate of energy dissipation (or energy slope). The depth of scour, however, was not significantly related to changes in bed slope (linear regression $p$-value $=0.504$ ). Figure 3 shows that there is much more scatter around the depth versus length regression line for Thompson's data, in which 
either bed slope or discharge was varied between runs, than for ours. Although the data we present here are for a fixed discharge only, Rodrigue-Gervais (2008) also measured scour depth and length when discharge varied. These points plot very close to our regression line in Figure 3, suggesting that changes in bed slope alter the relationship between pool length and depth, but that changes solely in discharge do not. In fact, Thompson (2002b) has commented that discharge affects both pool length and depth, unlike bed slope. Thus, the simple allometric relationship which we observed to predict volume is only of use in similar environments, where bed slopes are the same. Local variations in the resistance of the channel boundary, in nature, would be expected to further mask the connectivity we identified between pool depth, length and volume.

\section{Conclusion}

This study has examined the temporal evolution of scour near rough-surfaced deflectors for three overtopping flows. By maintaining identical approach flow conditions and changing the height of the structures, we have highlighted that reducing the overtopping ratio results in an increased depth and volume of scour. Additionally, the temporal evolution of scour next to submerged deflectors was demonstrated to be self-similar for high and medium structure heights ( $z / h$ of 1.22 and 1.83, respectively). However, the processes and location of maximum scour appeared different for a large overtopping ratio $(z / h=3.67)$. Future studies should investigate further the transition between relatively large overtopping ratios (from 2 to 3.5) to determine if a threshold exists or if these changes occur gradually. Such studies would be beneficial in the development of models capable of predicting scour depth near deflector-like structures in natural rivers, where overtopping conditions are very common.

\section{Acknowledgements}

This research was funded by an NSERC Discovery grant (Biron). Thanks to Susan Gaskin for granting access to the Civil Engineering Hydraulics Laboratory flume, and to John Bartczak for his invaluable help in the lab. Comments from three anonymous reviewers, the associate editor and the editor on a previous version greatly helped improve this paper. 


\section{References}

Ahmed, F. and Rajaratnam, N. (1998). "Flow around bridge piers." Journal of Hydraulic Engineering, ASCE, 124(3), 288-300.

Biron, P. M., Lane, S. N, Roy, A. G., Bradbrook, K. F. and Richards, K. S. (1998). "Sensitivity of bed shear stress estimated from vertical velocity profiles: the problem of sampling resolution." Earth Surface Processes and Landforms, 23, 133-139.

Biron, P. M., Robson, C., Lapointe, M. F. and Gaskin, S. J. (2004a). "Deflector designs for fish habitat restoration." Environmental Management, 33(1), 25-35.

Biron, P. M., Robson, C., Lapointe, M. F. and Gaskin, S. J. (2004b). "Comparing different methods of bed shear stress estimates in simple and complex flow fields." Earth Surface Processes and Landforms, 29(11), 1403-1415.

Biron, P. M., Robson, C., Lapointe, M. F. and Gaskin, S. J. (2005). “Three-dimensional flow dynamics around deflectors." River Research and Applications, 21, 961-975.

Dey, S., and Barbhuiya, A. K. (2006). "3D flow field in a scour hole at a wing-wall abutment." Journal of Hydraulic Research, 44(1), 33-49.

Dey, S., Raikar, R. V. and Roy, A. (2008). "Scour at submerged cylindrical obstacles under steady flow." Journal of Hydraulic Engineering, ASCE, 134(1), 105-109.

Ettema, R., Arndt, R., Roberts, P. and Wahl, T. (2000). Hydraulic Modeling: Concepts and Practice. Virginia: ASCE Publications, 390p.

Goring, D. G. and Nikora, V. I. (2002). "Despiking acoustic Doppler velocimeter data.” Journal of Hydraulic Engineering, ASCE, 128(1), 117-126.

Hey, R. D. (1994). "Environmentally sensitive river engineering.” In The Rivers Handbook: Hydrological and Ecological Principles, Calow, P. and Petts, G. E. (Eds.), Blackwell Scientific Publications, Oxford, UK, 337-362.

Kuhnle, R. A., Alonso, C. V., and Shields, F. D., Jr. (1999). "Geometry of scour holes associated with $90^{\circ}$ spur dikes.” Journal of Hydraulic Engineering, ASCE, 125(9), 972-978.

Kuhnle, R. A. Alonso, C. V., and Shields, F. D., Jr. (2002). "Local scour associated with angled spur dikes.” Journal of Hydraulic Engineering, ASCE, 128(12), 1087-1093.

Kuhnle, R. A., Jia, Y. and Alonso, C. V. (2008). "Measured and simulated flow near a submerged spur dike.”, Journal of Hydraulic Engineering, ASCE, 134(7), 916-924.

Kwan, R. T. F. and Melville, B. W. (1994). "Local scour and flow measurements at bridge abutments.", Journal of Hydraulic Research, 32(5), 661-673. 
McCoy, A., Constantinescu, G. and Weber, L. (2007). "A numerical investigation of coherent structures and mass exchange processes in channel flow with two lateral submerged groynes." Water Resources Research, 43, W05445, doi:10.1029/2006WR005267.

Melville, B.W. (1992) "Local scour at bridge abutments." Journal of Hydraulic Engineering, ASCE, 118(4), 615-630.

Melville, B. W. (1995). "Bridge abutment scour in compound channels." Journal of Hydraulic Engineering, ASCE, 121(12), 863-868.

Melville, B. W. (1997). "Pier and abutment scour: Integrated approach." Journal of Hydraulic Engineering, ASCE, 123(2), 125-136.

Melville, B. W. and Chiew, Y.-M. (1999). "Time scale for local scour at bridge piers." Journal of Hydraulic Engineering, ASCE, 125(1), 59-65.

Oliveto, G. and Hager, W. H. (2002). "Temporal evolution of clear-water pier and abutment scour.” Journal of Hydraulic Engineering, ASCE, 128(9), 811-820.

Rodrigue-Gervais, K. (2008) "Investigation of temporal scour development and flow dynamics around submerged deflectors in a laboratory flume." Unpublished M.Sc. thesis, Department of Geography, McGill University.

Rundquist, L. A. and Baldrige, J. E. (1990). "Fish habitat considerations." In Cold Regions Hydrology and Hydraulics, Ryan, W. L. and Crissman, R. D. (Eds), American Society of Civil Engineers, Technical Council on Cold Regions Engineering Monograph, New York, 579-613.

Swales, S. (1989). "The use of instream habitat improvement methodology in mitigating the adverse effects of river regulation on fisheries." In Gore, J. A. and Petts, G. E. (Eds) Alternatives in Regulated River Management. CRC Press Inc, Boca Raton, Florida, 186-208.

Thompson, D. M. (2002a). "Channel-bed scour with high versus low deflectors.” Journal of Hydraulic Engineering, ASCE, 128(6), 640-643.

Thompson, D. M. (2002b). "Geometric adjustment of pools to changes in slope and discharge: a flume experiment." Geomorphology, 46, 257-265.

Tominaga, A., Nakano, Y. and Fujita, T. (2000), "Visualization analysis of flow structures in submerged spur dikes.” Annual Journal of Hydraulic Engineering, 44, 1041- 1045.

Uijttewaal, W. (2005). "Effects of groyne layout on the flow in groyne fields: Laboratory experiments.” Journal of Hydraulic Engineering, ASCE, 131, 782- 794.

Yalin, M. S. and Karahan, E. (1979). "Inception of sediment transport." Journal of the Hydraulics Division, ASCE, 105(11), 1433-1443. 
Table 1 Best-fit equations for the temporal development of normalized scour depth

\begin{tabular}{|l|l|l|c|c|}
\hline \multicolumn{1}{|c|}{ Run \# } & \multicolumn{1}{|c|}{ Equation } & $R^{2}$ & $\begin{array}{c}\text { Standard } \\
\text { deviation of } \\
\text { residuals }(\%)\end{array}$ & $\begin{array}{c}\text { Wald-Wolfowitz runs } \\
\text { test }\end{array}$ \\
\hline $\mathrm{H} 90-1$ & $\mathrm{~d}_{\mathrm{s}} / \mathrm{d}_{\mathrm{e}}=0.996\left(\mathrm{t} / \mathrm{t}_{\mathrm{e}}\right)^{0.112}$ & 0.990 & 1.021 & Random distribution \\
\hline $\mathrm{H} 90-2$ & $\mathrm{~d}_{\mathrm{s}} / \mathrm{d}_{\mathrm{e}}=1.011\left(\mathrm{t} / \mathrm{t}_{\mathrm{e}}\right)^{0.133}$ & 0.993 & 1.021 & Random distribution \\
\hline $\mathrm{H} 90-3$ & $\mathrm{~d}_{\mathrm{s}} / \mathrm{d}_{\mathrm{e}}=0.157 \ln \left(\mathrm{t} / \mathrm{t}_{\mathrm{e}}\right)+0.942$ & 0.987 & 1.033 & Significant clusters \\
\hline
\end{tabular}

Table 2 Equilibrium scour depth, length and volume

\begin{tabular}{|l|c|c|c|}
\hline \multicolumn{1}{|c|}{ Run \# } & Depth $(\mathrm{cm})$ & Length $(\mathrm{cm})$ & Volume $\left(\mathrm{cm}^{3}\right)$ \\
\hline H90-1 & 11.7 & 76.6 & 4719.9 \\
\hline H90-2 & 8.3 & 42.1 & 2234.7 \\
\hline H90-3 & 5.0 & 21.0 & 366.9 \\
\hline
\end{tabular}




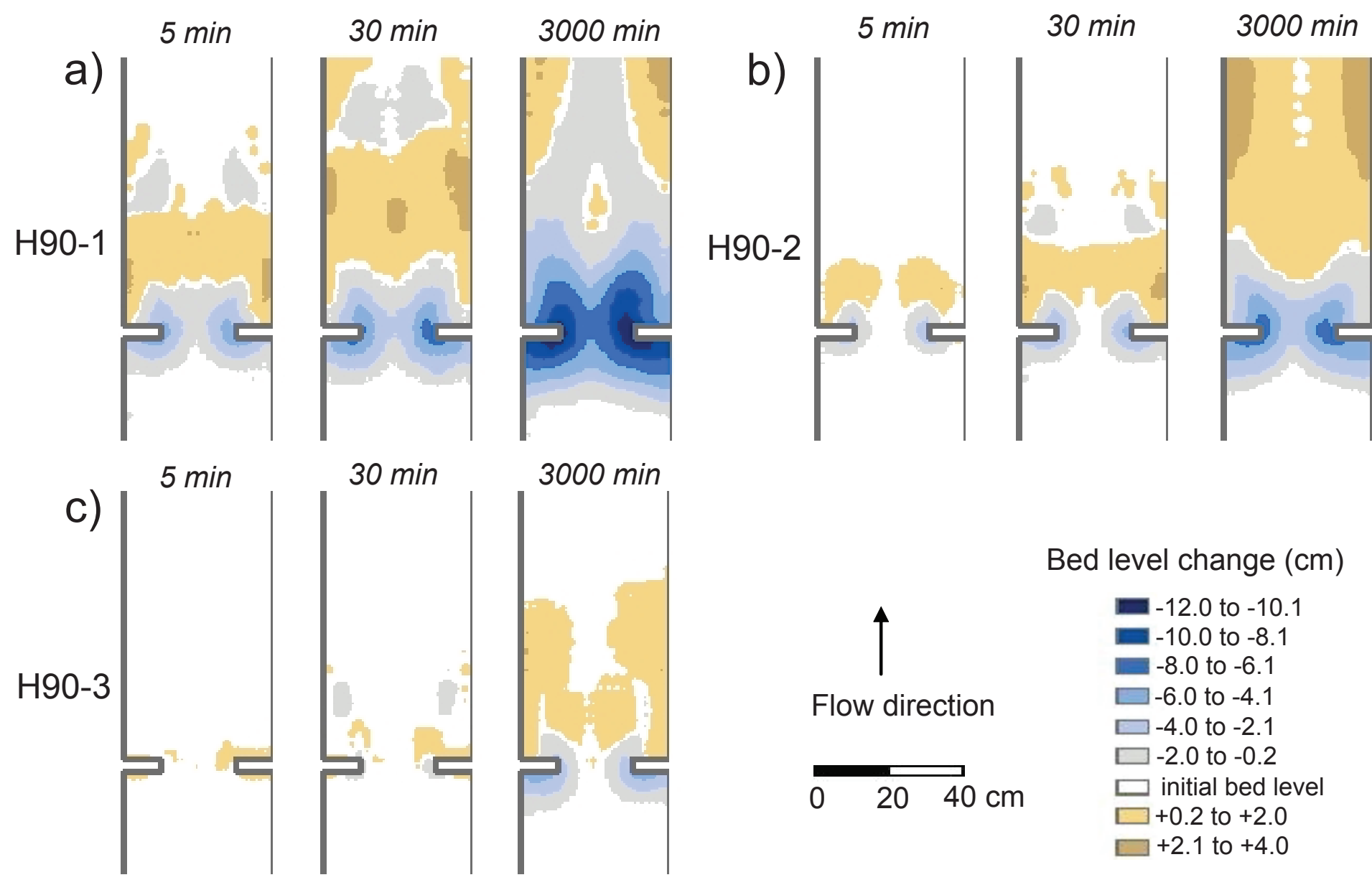

Figure 1 Temporal evolution of bed topography for different runs. 

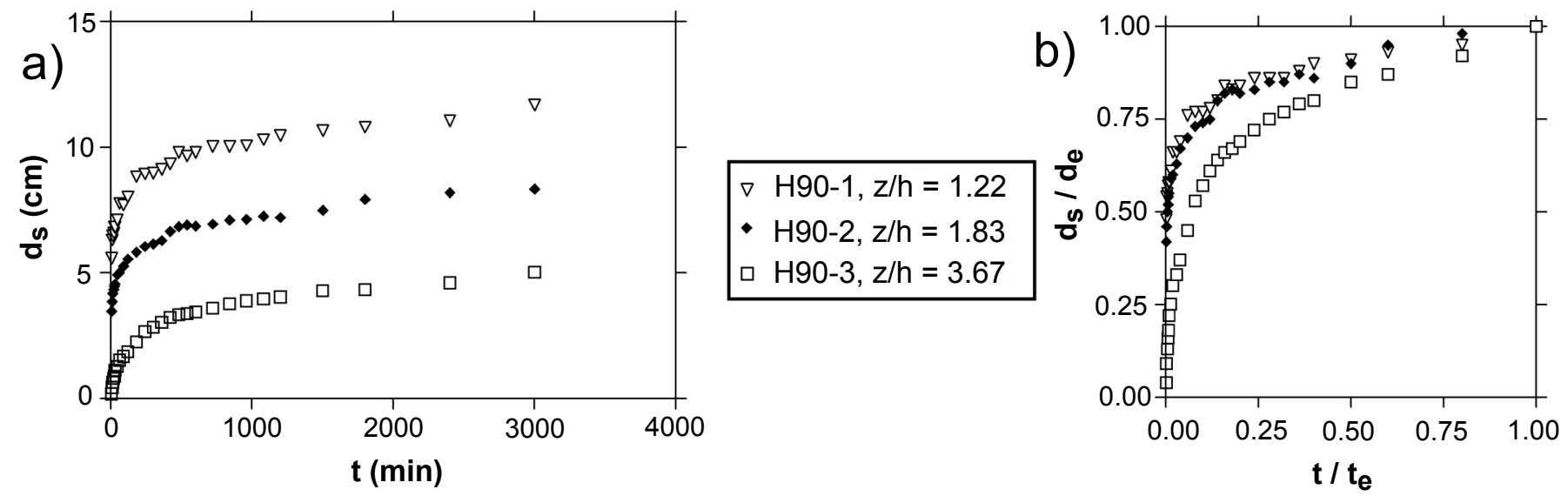

Figure 2 Evolution of scour depth with time for the three $\mathrm{H} 90$ series using (a) raw values and (b) values normalized with equilibrium values.. 


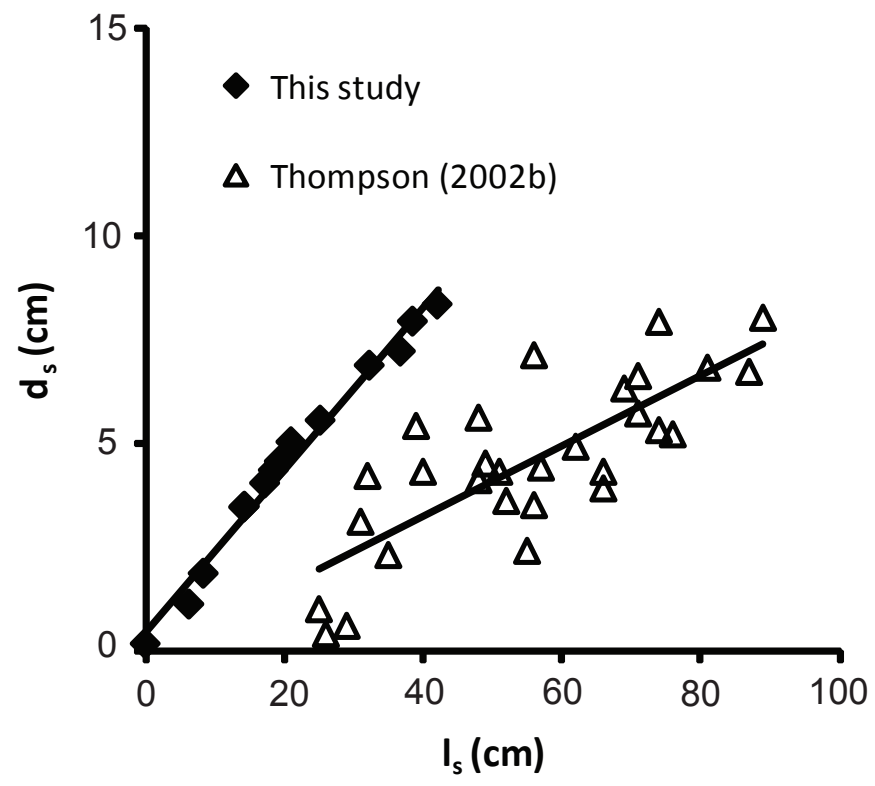

Figure 3 Scour depth versus pool length for this study and Thompson's (2002b) data. 